CHALCOSIS

ButLer, H. (1929)._Trans. Ophthal. Soc. U.K., Vol. XLIX, p. 446. CHRYSEOSIS

Bonnet and Bonamour (1936).-Bull. Soc. Ophtal. Paris, p. 528. (1937).-Ibid., p. 751.

BonNet, Bonamour and El Khalifah (1939)._Arch. d'Ophtal. Vol. III, p. 385. HYDRARGYROSIS

Atrinson, W. S. (1943).-Amer. Jl. of Ophthal., Vol. XXVI, p. 685.

$8 \mathrm{~b}$,

ARGYROSIS

BISChLER, V. (1942).-Ophthalmologica, Vol. CIII, p. 281.

This paper contains numerous references to the various forms of metallic impregnation of the cornea.

\title{
POST-OPERATIVE INTRA-OCULAR INFECTION CONTROLLED BY PENICILLIN*
}

\author{
F. S. LAVERY \\ DUBLIN
}

As cases which develop intra-ocular infection following upon cataract extraction almost invariably do badly I am reporting the following case which, as a result of using penicillin, has proved an exception to the rule.

J. D., aged 65 years, had a tombined extra-capsular extraction done on his right eye on September 27, 1947, Although there was some cortical remains no wash-out was employed. The appearance of the eye was satisfactory until four days later when the cornea became hazy and the iris presented a muddy appearance. He was put on sulphadiazine tablets, four as an initial dose, and two fourhourly as maintainance dose. Penicillin drops (5000 units per c.c.) were instilled hourly. Next day the condition of the eye showed a marked deterioration. There was pus in the anterior chamber and the wound edges were infected. 50,000 units of penicillin were injected sub-conjunctivally, and 500,000 intra-muscularly every four hours. The sub-conjunctival injections were repeated on the two days following, and the intra-muscular injections were continued for four days. On the third day after the first sub-conjunctival injection of penicillin the condition of the eye showed a marked improvement. The wound edges were now healthy and the pus had been absorbed from the anterior chamber. He was discharged from hospital four weeks from the date of operation. The eye was quiet. The projection of light was accurate, and it is expected that capsulotomy will give him good vision in the eye. When the patient was re-admitted in December, 1947, it was found that a capsulotomy was not required, the corrected vision in the eye being $6 / 6$.

\footnotetext{
${ }^{*}$ Received for publication, November 4, 1947.
} 